\title{
DoMINO: Donor milk for improved neurodevelopmental outcomes
}

\author{
Sharon Unger ${ }^{1}$, Sharyn Gibbins ${ }^{2}$, John Zupancic ${ }^{3}$ and Deborah L O'Connor ${ }^{4 *}$
}

\begin{abstract}
Background: Provision of mother's own milk is the optimal way to feed infants, including very low birth weight infants (VLBW, <1500 g). Importantly for VLBW infants, who are at elevated risk of neurologic sequelae, mother's own milk has been shown to enhance neurocognitive development. Unfortunately, the majority of mothers of VLBW infants are unable to provide an adequate supply of milk and thus supplementation with formula or donor milk is necessary. Given the association between mother's own milk and neurodevelopment, it is important to ascertain whether provision of human donor milk as a supplement may yield superior neurodevelopmental outcomes compared to formula.

Our primary hypothesis is that VLBW infants fed pasteurized donor milk compared to preterm formula as a supplement to mother's own milk for 90 days or until hospital discharge, whichever comes first, will have an improved cognitive outcome as measured at 18 months corrected age on the Bayley Scales of Infant Development, $3^{\text {rd }}$ ed. Secondary hypotheses are that the use of pasteurized donor milk will: (1) reduce a composite of death and serious morbidity; (2) support growth; and (3) improve language and motor development. Exploratory research questions include: Will use of pasteurized donor milk: (1) influence feeding tolerance and nutrient intake (2) have an acceptable cost effectiveness from a comprehensive societal perspective?

Methods/Design: DoMINO is a multi-centre, intent-to-treat, double blinded, randomized control trial. VLBW infants ( $n=363$ ) were randomized within four days of birth to either (1) pasteurized donor milk or (2) preterm formula whenever mother's own milk was unavailable. Study recruitment began in October 2010 and was completed in December 2012. The 90 day feeding intervention is complete and long-term follow-up is underway.

Discussion: Preterm birth and its complications are a leading cause long-term morbidity among Canadian children. Strategies to mitigate this risk are urgently required. As mother's own milk has been shown to improve neurodevelopment, it is essential to ascertain whether pasteurized donor milk will confer the same advantage over formula without undue risks and at acceptable costs. Knowledge translation from this trial will be pivotal in setting donor milk policy in Canada and beyond.
\end{abstract}

Trial registration: ISRCTN35317141; Registered 10 August 2010.

Keywords: Human milk, Donor milk, Neurodevelopment, Very low birth weight infants

\footnotetext{
* Correspondence: deborah.oconnor@utoronto.ca

${ }^{4}$ University of Toronto and The Hospital for Sick Children, 327 Fitzgerald

Building, 150 College Street, Toronto, Ontario, M5S 3E2, Canada

Full list of author information is available at the end of the article
} 


\section{Background}

Technological advances in the neonatal intensive care unit (NICU) have greatly enhanced the survival rate of very low birth weight (VLBW) infants $(<1500 \mathrm{~g})$. In developed countries, more than $90 \%$ of infants born $<32$ weeks gestation now survive initial hospitalization [1]. Coincident with this improved survival, VLBW birth is an important cause of long-term neurological morbidity in childhood. Interventions which reduce morbidity and promote normal brain development for VLBW infants are thus urgently required $[2,3]$.

\section{Neurodevelopmental outcomes of VLBW infants and the role of mother's own milk}

Many VLBW infants show continued neurologic sequelae such as cognitive deficits, academic underachievement, grade failures and the need for remedial assistance during childhood and middle adolescence [3]. Aside from intracranial lesions associated with preterm birth, factors shown to impact the neurodevelopmental outcome of VLBW infants include gestational age at birth, sepsis, necrotizing enterocolitis (NEC), chronic lung disease, suboptimal nutrient intake or poor growth [2-8]. Compelling evidence exists to suggest that use of mother's own breastmilk compared to infant formula during initial hospitalization positively affects the neurodevelopment of VLBW infants during early childhood and beyond [9-15]. Vohr et al. demonstrated a dose dependent relationship between breastmilk intake for extremely low birth weight infants enrolled in the National Institute of Child Health and Human Development Glutamine Trial. For every $10 \mathrm{~mL} / \mathrm{kg} /$ day increase in breastmilk intake, there was an associated increase in the Bayley Mental Development Index of 0.53 at 18 months corrected age (CA) [14] which persisted to 30 months CA [15]. The impact of this can be seen to be quite dramatic when comparing a baby who received no breastmilk to one who received $150 \mathrm{~mL} / \mathrm{kg} /$ day which would equate to a difference of 7.5 points.

Mother's own milk is thought to improve neurodevelopment because it is well tolerated by the VLBW infant, facilitating the transition from parenteral to enteral feeding, and due to its nutrient composition (with fortification as appropriate); both factors resulting in the provision of optimal substrate for brain development. Additionally, mother's milk, via a myriad of bioactive components such as secretory IgA, lactoferrin and growth factors, protects from morbidities associated with preterm birth (NEC, sepsis, other infections) that are in turn additive risk factors for an adverse neurological outcome $[9,15,16]$.

\section{Use of mother's own milk in the VLBW population}

The World Health Organization, the American Academy of Pediatrics and the Canadian Paediatric Society all recommend mother's own milk as the exclusive source of feeding for infants during their first 6 months of life [17-19]. Despite the many advantages of feeding mother's own milk, the majority of mothers of VLBW infants, for a variety of reasons such as illness, stress, mammary secretory cell immaturity and other factors related to preterm birth, are unable to express adequate amounts of milk to exclusively feed their children [20]. A smaller percentage of mothers choose not to pump their breasts to provide breastmilk.

\section{Use of pasteurized donor human milk}

In North America, preterm formula is increasingly being replaced by pasteurized donor human milk when a supplement to mother's own milk is required for VLBW infants. Currently there are three non-profit donor milk banks in Canada and eleven in the United States with more in the planning stages [21]. There is currently one for profit company in the United States that partners with NICUs to provide donor milk. There remains however a paucity of scientific research with respect to pasteurized donor milk use in the NICU.

In a Cochrane systematic review and meta-analysis, Quigley et al. demonstrated both benefits and risks associated with the use of donor milk [22]. See Table 1 for a summary of the individual studies included in this review. Importantly, there was a higher incidence of NEC among infants with birth weights $<2500 \mathrm{~g}$ and fed formula versus those fed donor milk (relative risk of 2.5 [95\% CI, 1.2, 5.1]). Because NEC is the most common gastrointestinal emergency among VLBW infants, its prevention is a powerful argument in favor of donor milk as an alternative supplement to formula when mother's own milk is not available [23]. NEC may lead to perforation of the bowel, bowel resection and death or long-term feeding problems associated with a shortened gastrointestinal tract [23]. Further, NEC, particularly surgical NEC has been shown to be associated with adverse neurodevelopment outcomes at 18-24 months CA [24].

The Quigley et al. review and meta-analysis, however, concluded that infants fed donor milk experienced slower weight $(p<0.0001)$, length $(p<0.0003)$ and head circumference $(p<0.0001)$ gains than those fed formula. These risks associated with donor milk are of significant concern because VLBW infants are born with impoverished nutrient reserves, and are subject to metabolic stresses that further elevate nutritional requirements $[22,23]$. Nutrient deficits and sub-optimal growth has significant long term neurodevelopmental consequences $[2,23,24,33,34]$.

Quigley et al. point out that all but one of the randomized controlled trial (RCTs) examined in their metaanalysis were $>25$ years old when smaller VLBW infants did not survive. Feeding practices have also since 
Table 1 Formula milk versus donor milk for feeding preterm or low birth weight infants (Cochrane review)

\begin{tabular}{|c|c|c|c|c|c|c|}
\hline Author & Year & Subjects & Comparison & Blind & Primary outcome & Notes \\
\hline Davies [25] & 1977 & $\begin{array}{l}68 \text { preterm } \\
\text { (28-36 weeks) }\end{array}$ & Term formula vs Donor Milk & No & $\begin{array}{l}\text { Slower growth first month for } \\
\text { Donor Milk }\end{array}$ & $\begin{array}{l}\text { Uncertain group for } 2 \text { infants } \\
\text { with mother's own milk }\end{array}$ \\
\hline Gross [26] & 1983 & $\begin{array}{l}67 \text { preterm } \\
\text { (27-33 weeks) }\end{array}$ & Term formula vs Donor Milk & No & $\begin{array}{l}\text { Slower growth for term Donor } \\
\text { Milk (not preterm Donor Milk) }\end{array}$ & $\begin{array}{l}\text { Infants with feed intolerance/NEC } \\
\text { withdrawn from growth analysis }\end{array}$ \\
\hline Lucas [27] & 1984 & $\begin{array}{l}159 \text { LBW } \\
(<1850 \mathrm{~g})\end{array}$ & Preterm formula vs Donor Milk & No & $\begin{array}{l}\text { Slower growth for Donor Milk; } \\
\text { no neurodevelopmental difference }\end{array}$ & \\
\hline Lucas [28] & 1984 & $\begin{array}{l}343 \text { LBW } \\
(<1850 \mathrm{~g})\end{array}$ & Preterm formula vs Donor Milk & No & No neurodevelopmental difference & \\
\hline Raiha [29] & 1976 & $\begin{array}{l}106 \text { LBW } \\
(<2100 \mathrm{~g})\end{array}$ & Term formula vs Donor Milk & No & No difference in growth & \\
\hline Schanler [30] & 2005 & $\begin{array}{l}173 \text { preterm } \\
(<30 \text { weeks })\end{array}$ & $\begin{array}{l}\text { Term formula vs Fortified } \\
\text { Donor Milk }\end{array}$ & Yes & $\begin{array}{l}\text { Slower growth for Donor Milk, } \\
\text { no difference in infection events }\end{array}$ & $\begin{array}{l}\text { Only fortified Donor Milk study; } \\
20 \% \text { cross-over from Donor Milk } \\
\text { to Formula }\end{array}$ \\
\hline Schultz [31] & 1980 & 20 preterm & Term formula vs Donor Milk & No & No difference in weight gain & \\
\hline Tyson [32] & 1983 & $\begin{array}{l}81 \text { LBW } \\
(<1500 \mathrm{~g})\end{array}$ & Preterm formula vs Donor Milk & No & Slower growth for Donor Milk & $\begin{array}{l}\text { Donor Milk not pasteurized; } \\
\text { Randomized day 10; } 5 \text { affected } \\
\text { infants withdrawn }\end{array}$ \\
\hline
\end{tabular}

Quigley MA, Henderson G, Anthony MY, McGuire W. Formula milk versus donor breast milk for feeding preterm or low birth weight infants. Cochrane Database Syst Rev 2007:CD002971.

changed to include preferential use of mother's own milk along with nutrient fortification of human milk to promote adequate growth. There was only one RCT [30] in the Cochrane review that was reflective of current clinical practice which includes much smaller babies, preferential use of mother's own milk and nutrient fortification. This study however did not look at long-term neurocognitive outcomes.

\section{Effects of the pasteurization process}

The donor milk used in North American NICUs is typically pooled from 3 or more mothers to reduce batch-to-batch variability in nutrient composition and is pasteurized (Holder pasteurization, $62.5^{\circ} \mathrm{C}$ for 30 minutes) according to Human Milk Banking Association of North America (HMBANA) guidelines to prevent the transmission of infectious agents (e.g. HIV, pathogenic bacteria [35]). Despite pooling, donated milk often contains a lower concentration of energy, protein, fatty acids and other nutrients compared to mother's own milk due to the fact that the donations usually come from mothers who deliver a healthy term infant several weeks or months after delivery once they have accrued a surplus of pumped milk [36-38]. It is well known that the concentration of a number of nutrients, most especially protein, are higher in the breastmilk of mothers delivering preterm compared to that of mothers of term born infants $[39,40]$. Further, the concentration of many nutrients in breastmilk decline with the progression of lactation [39]. While many nutrients are unaffected, Holder pasteurization will impact the concentration of some nutrients in breastmilk, most notably a number of the water soluble vitamins (e.g. folate and vitamin C)
[41,42] (Table 2). Further, donor milk, compared to mother's own milk, also undergoes at least one additional collection/storage container transfer and freeze-thaw cycle, as part of the pasteurization process affecting the concentration of many nutrients in breastmilk as fat adheres to the walls of each vessel [39].

Very little is known about the impact of the pasteurization process on the myriad of bioactive components in human milk, many of which serve a dual role in nutrient absorption and as anti-infective agents [66]. Holder pasteurization reduces the concentration of immunoglobins (secretory IgA, G and M) [48,58,67]. Live cellular components, including $\mathrm{B}$ and $\mathrm{T}$ lymphocytes are eliminated (Table 2). Of the few enzymes that have been studied, milk amylase is relatively unaffected, lysozyme in more recent reports has been shown to be affected and lipases are completely denatured $[44,48,58,59,67]$. Fat absorption is lower in donor versus mother's own milk-fed infants, presumably due in part to destruction of bile salt stimulated lipase known to compensate for low intraluminal lipase activities necessary for fat absorption [68]. Lactoferrin, an anti-microbial and immunomodulatory iron-binding glycoprotein shown in both animal studies and a recent clinical trial to be effective against neonatal sepsis is reduced by $80 \%[58,69,70]$. Immune modulators known to be important in NEC prevention such as IFN- $\gamma$, TNF- $\alpha$, IL- $1 \beta$. IL-10 and hepatocyte growth factor remain present in donor milk post pasteurization however in significantly reduced quantities [54].

\section{Study objectives}

The primary question is whether the use of pasteurized donor milk, compared to preterm formula, as a supplement 
Table 2 Breastmilk components and the effect of pasteurization

\begin{tabular}{|c|c|c|}
\hline Component & Effect & References \\
\hline Adiponectin & $33 \%$ reduction & [43] \\
\hline Amylase & $15 \%$ loss of activity & [44] \\
\hline B-cells, T-cells & Abolished & {$[45,46]$} \\
\hline Bile salt dependent lipase & Abolished & [44] \\
\hline CD14 (soluble) & $88 \%$ reduction & {$[47]$} \\
\hline \multicolumn{3}{|l|}{ Fats: } \\
\hline Total fat & No effect & {$[48-50]$} \\
\hline C14:1-C24:1 & No effect & {$[44,49]$} \\
\hline $\mathrm{C} 8: 0-\mathrm{C} 24: 0$ & No effect & {$[44,49]$} \\
\hline n-3,n-6 PUFA & No effect & {$[44,49]$} \\
\hline $\mathrm{AA}, \mathrm{DHA}$ & No effect & {$[44,49]$} \\
\hline Linoleic, linolenic & Reduced & {$[51]$} \\
\hline Calcium & No effect & {$[48]$} \\
\hline Copper & $9 \%$ reduction No effect & {$[50,52]$} \\
\hline Escherichia coli inhibition & $26 \%$ reduction & [53] \\
\hline Epidermal growth factor & No effect & {$[54,55]$} \\
\hline Erythropoeitin & Significantly reduced & {$[56]$} \\
\hline Folate & $16-31 \%$ reduction & {$[41,42]$} \\
\hline Free fatty acids & $80 \%$ increase & {$[57]$} \\
\hline Gangliosides & No effect & [54] \\
\hline Hepatocyte growth factor & $60 \%$ reduction & {$[54]$} \\
\hline \multicolumn{3}{|l|}{ Immunoglobulins: } \\
\hline $\lg A, s \lg A$ & 0-48\% reduction & {$[45,46,48,58-62]$} \\
\hline $\lg G$ & $34 \%$ reduction & {$[60]$} \\
\hline $\lg M$ & Abolished & {$[61,62]$} \\
\hline Insulin & $46 \%$ reduction & [43] \\
\hline IGF-1, IGF-2, IGF-BP2,3 & 7-39\% reduction & {$[55]$} \\
\hline$\| L-1 \beta, I L-10$ & Significantly reduced & {$[54,56]$} \\
\hline IL-2, II-4, IL-5, IL-12, IL-13 & No effect & {$[54]$} \\
\hline IL-8 & Increased & {$[54]$} \\
\hline Interferon gamma & Significantly reduced & {$[54]$} \\
\hline Iron & 0-15\% reduction & {$[50,52]$} \\
\hline Lactate & $7 \%$ reduction & {$[57]$} \\
\hline Lactoferrin & $57-80 \%$ reduction & {$[58,60,61]$} \\
\hline Lactose & No effect & {$[48,50]$} \\
\hline Lipoprotein lipase & Abolished & [44] \\
\hline Lysine & Significantly reduced & {$[61,63]$} \\
\hline Lysozyme activity & No effect $24-60 \%$ reduction & {$[58-62]$} \\
\hline Lymphocytes & Abolished & {$[46]$} \\
\hline Magnesium & No effect & {$[48]$} \\
\hline Mannose-binding lectin & No effect & {$[47]$} \\
\hline Oligosaccharides & No effect & {$[64]$} \\
\hline Phosphorus & No effect & {$[48]$} \\
\hline
\end{tabular}

Table 2 Breastmilk components and the effect of pasteurization (Continued)

\begin{tabular}{lll}
\hline Potassium & No effect & {$[48]$} \\
Protein & No effect Reduced & {$[43,48,50,62]$} \\
Sodium & No effect & {$[48,50]$} \\
TGF- $a$, TGF- $\beta$ & No effect Reduced & {$[54,65]$} \\
Vitamin A & No effect & {$[50]$} \\
Vitamin B6 & $15 \%$ reduction & {$[42]$} \\
Vitamin C & $36 \%$ reduction & {$[42]$} \\
Zinc & $0-3 \%$ reduction & {$[50,52]$} \\
\hline
\end{tabular}

Modified with permission from: Ewaschuk JB, Unger S, Harvey S, O'Connor DL, Field CJ. Effect of pasteurization on immune components of milk: implications for feeding preterm infants. Applied Physiology, Nutrition, and Metabolism $36: 175-182,2011$.

to mother's own milk for the first 90 days after randomization or until hospital discharge, whichever comes first, improves cognitive development of VLBW infants at 18 months corrected age as measured by the Bayley Scales of Infant Development, $3^{\text {rd }}$ edition (BSID). Secondary questions are whether donor milk will reduce a composite of death and serious morbidity (NEC, late onset sepsis, chronic lung disease and severe retinopathy of prematurity); support growth; and improve language and motor development at 18 months corrected age. Exploratory research questions include: will use of donor milk, as a supplement to mother's own milk: (1) influence feeding tolerance and nutrient intake (2) have an acceptable cost effectiveness (medical and non medical) from comprehensive societal perspective?

\section{Methods/Design}

This is a pragmatic multi-centre, double-blind, RCT designed to evaluate the effectiveness of pasteurized donor milk as a supplement to mother's own milk in those infants when mother's own milk is unavailable. The analysis will be conducted using an "intention to treat" approach. Infants randomized to the intervention group received donor milk when mother's own milk was unavailable. Infants randomized to the control group received formula designed for preterm infants when mother's own milk was unavailable.

Funding was received from the Canadian Institutes for Health Research (MOP\#210093), SickKids Foundation and the Ministry of Health and Longterm Care of Ontario. Infants were recruited in one of four participating level III NICU in Toronto and Hamilton, Canada. A comprehensive list of parental and infant demographic variables was collected after written informed consent was secured (Table 3). Randomization, performed within 96 hours of birth, was done centrally using a $24 \mathrm{hr}$ /day web-based third party randomization service (Centre for Mother Infant and Child Research, Toronto). The study 
Table 3 Demographic variables collected during the DoMINO trial

\begin{tabular}{|c|c|}
\hline Infant characteristics & Prenatal and parental characteristics \\
\hline Gestational age at birth+ & Gravity/Parity* \\
\hline Birth weight, length and head circumference+ & Artificial reproductive technology (type and origin of eggs, sperm)+ \\
\hline $\begin{array}{l}\text { Size for gestational age (small [SGA], appropriate }[\mathrm{AGA}] \text { or } \\
\text { large for }[\mathrm{LGA} \text { gestational age)+ }\end{array}$ & Antibiotic use prior to delivery (prior 2 weeks)+ \\
\hline Sex+ & Use of Prenatal Steroids+ \\
\hline Multiple birth status+ & Cesarean delivery* \\
\hline 5-minute Apgar score+ & Mom has previously breastfed (yes/no)* \\
\hline \multirow[t]{9}{*}{ Newborn Illness severity score (SNAP-II+) } & Mom intends to breastfeed (yes/no)* \\
\hline & Parental education (highest degree or diploma attained)* \\
\hline & Parental weight and height (self-reported)* \\
\hline & Parental age* \\
\hline & Number of children in current household* \\
\hline & Smoking (maternal history during pregnancy)* \\
\hline & First language spoken in the home ${ }^{*}$ \\
\hline & Socioeconomic status (single parenting; above or below poverty line)* \\
\hline & Ethnicity* \\
\hline
\end{tabular}

Baseline demographic variables collected by means of parental interviews* or from medical records + .

allocation was randomly assigned in a ratio of 1:1, in random blocks of 4 and 8 , with stratification by centre and birth weight grouping (<1000 g and 1000-1499 g). Aside from the research dietary technicians assigned to the study and a single neonatal dietitian, all members of the research study team (including outcome assessors), clinical teams and families are blinded to study allocation.

The feeding intervention continued for 90 days including transfer to a participating level II unit or until discharge home, whichever occurred first. Other than whether infants received donor milk or preterm formula as a supplement, all other aspects of feeding were directed by the clinical team at each NICU. General feeding guidelines were agreed upon by the participating NICUs to provide a consistent approach, and to set criteria necessitating removal from the feeding protocol. These detailed guidelines are found in Table 4. Donor milk was purchased and shipped primarily from the Mother's Milk Bank of Ohio (>95\%) with backup from Calgary Mother's Milk Bank, both HMBANA members. Donor milk from Ohio was collected and pooled from at least three women who had delivered within the previous three months. Once nutrient fortification of donor milk commenced, a protein module $(0.3 \mathrm{~g} / \mathrm{dl}$, Beneprotein, Nestle) was added to donor milk to bring the analyzed protein content $(0.9 \mathrm{~g} / \mathrm{dl})$ up to the average estimated protein concentration of mother's own milk after 30 days $(1.2 \mathrm{~g} / \mathrm{dl})$ [71,72].

Each morning, a member of the health care team at each NICU completed and FAXed in a feeding order for study infants in their care to our research diet technicians. All study feeds for research participants were prepared in a single milk preparation room at the Hospital for Sick Children in a laminar flow cabinet. Feeds were delivered to units daily in amber single-use oral syringes (Baxa, Deerfield Illinois) or orange plastic wrapped bottles by study staff or courier. The contents of syringes and bottles were indistinguishable by visual inspection.

The frequency and duration of assessment during the feeding intervention and after hospital discharge are illustrated in Figure 1. During the feeding intervention, morbidity/mortality, growth, feeding tolerance, nutrient intake data and level of respiratory support (daily acuity index proxy) were extracted prospectively from the medical record or directly assessed on a weekly basis by a member of the study team. Following discharge home, infants are seen at clinic visits scheduled at 4, 8, 12 and, 18 months CA corresponding to important feeding, growth and developmental milestones. Additionally, families are called monthly after discharge to ascertain healthcare resources accessed on behalf of the child (e.g. visiting a pediatrician, home care). During these calls, information on current feeding practices is collected as these (e.g. duration of breastfeeding) may influence neurodevelopment.

A review of safety data (growth, major morbidity) occurred after one- and two-thirds of infants completed the feeding intervention by an external Data Safety and Monitoring committee. The study was approved by the Research Ethics Committee at each participating hospital.

\section{Inclusion/exclusion criteria}

The inclusion criteria were (1) day 1 to 4 of life; (2) <1500 g birth weight; (3) enteral feeding expected to be initiated 
Similac Special Care 20 or $24 \mathrm{kcal} / \mathrm{oz}$ [3.0 g protein/100 kcal] [Abbott Laboratories] or

Enfamil Premature Formula 20 or $24 \mathrm{kcal} / \mathrm{oz}$ [3.0 g protein/100 kcal] [Mead Johnson Nutritionals]

\section{Initiation of enteral feeding}

Volume of feeding at initiation

\section{Rate of feed advancement}

Fortification to commence at $>120 \mathrm{ml} / \mathrm{kg} /$ day

using milk pumped $>7$ days after parturition +

\section{Volume}

Minimum protein dose to be provided once (or up to 3 days after) volume reaches $>150 \mathrm{ml} / \mathrm{kg} / \mathrm{d}$

\section{Day $1-7$}

$10-20 \mathrm{ml} / \mathrm{kg} / \mathrm{d}$ (hold volume for 3-5 days)

$10-25 \mathrm{ml} / \mathrm{kg} / \mathrm{day}$

Human milk fortifier

Enfamil Human Milk Fortifier, [Mead Johnson Nutritionals] or

Similac Human Milk Fortifier, [Abbott Laboratories]

$140-200 \mathrm{ml} / \mathrm{kg} / \mathrm{d}$ to achieve a weight gain of $>15 \mathrm{~g} / \mathrm{kg} / \mathrm{day}$

$3.0 \mathrm{~g} / \mathrm{kg} / \mathrm{d}^{* *}$
Day 1-7

$10-20 \mathrm{ml} / \mathrm{kg} / \mathrm{d}$ (hold volume for 3-5 days)

$10-25 \mathrm{ml} / \mathrm{kg} /$ day

Not Applicable

$140-200 \mathrm{ml} / \mathrm{kg} / \mathrm{d}$ to achieve a weight gain of $>15 \mathrm{~g} / \mathrm{kg} / \mathrm{day}$

$3.0 \mathrm{~g} / \mathrm{kg} / \mathrm{d}^{* *}$

At $24 \mathrm{kcal} / \mathrm{oz}$ and weight gain $<15 \mathrm{~g} / \mathbf{k g} / \mathbf{d}$ for 3-7 days Concentrate feeding using a multi-nutrient modular to 26-27 kcal/oz Modular to 26-27 kcal/oz

At $27 \mathrm{kcal} / \mathrm{oz}$ and weight gain $<\mathbf{1 5} \mathbf{~ g} / \mathbf{k g} / \mathbf{d}$ for 3-7 days Concentrate feeding using a multi-nutrient modular to $30 \mathrm{kcal} / \mathrm{oz}$ Concentrate feeding using a multinutrient modular to $30 \mathrm{kcal} / \mathrm{oz}$

At $30 \mathrm{kcal} / \mathrm{oz}$ and weight gain $<15 \mathrm{~g} / \mathbf{k g} / \mathbf{d}$ for 3-7 days Remove from feeding protocol Remove from feeding protocol

*A low or high iron formula will be used for study infants at each NICU depending on the iron content of the human milk fortifier in use to avoid unblinding of feeding assignments.

+Commence supplementation with 200-400 IU vitamin D and 2-4 mg/kg/d elemental iron.

${ }^{*}$ As infants approach their estimated date of delivery and/or readied for hospital discharge intakes will usually be below this value. 


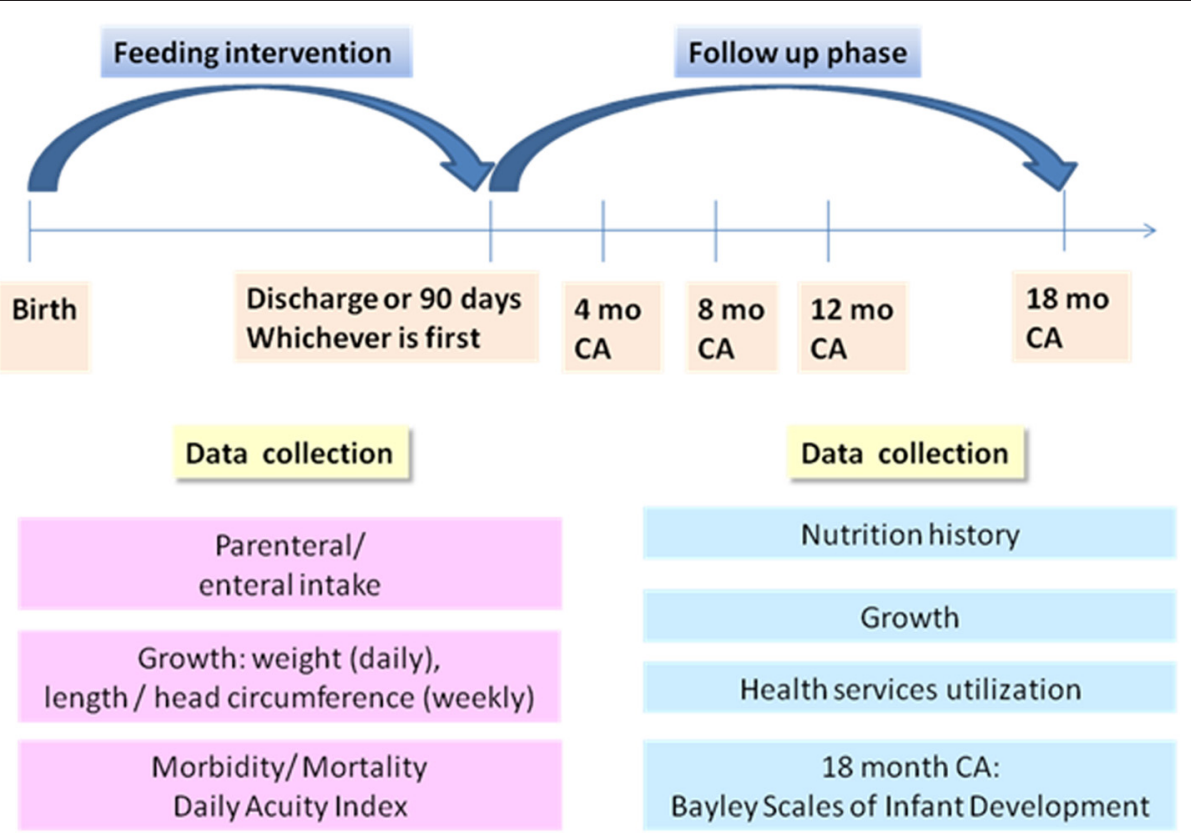

Figure 1 Frequency and duration of follow up.

in the first 7 days of life. The exclusion criteria were (1) infants with serious congenital or chromosomal anomalies that may contribute to poor developmental outcome; (2) severe asphyxia; (3) enrolment in any other clinical study affecting nutritional management during the feeding intervention; (4) reasonable potential that the infant would be transferred to a NICU where the study protocol could not be continued. The study feeding protocol was stopped if (1) the infant died during the intervention period; (2) a parent(s) requested withdrawal from the feeding protocol; (3) the infant had inadequate weight gain despite nutrient concentration of feedings (4) there was a requirement for thickening of feeds that would unmask the feeding assignment. In the event that an infant was withdrawn from the study feeding protocol, the family was requested to allow Research Staff to continue data collection and to complete the follow-up phase after discharge. See Figure 2 for a review of subject disposition to date.

\section{Outcome measures}

The primary outcome for this trial is the cognitive composite score on the BSID-III at 18 months CA. The BSIDIII is a standardized test designed to assess the cognitive, language and motor (fine, gross) development of infants from 1 to 42 months of age [73]. A decision was made to administer this test at each infant's 18 month CA birth date because of the improved predictive validity at this time compared to earlier ages [73,74].
The secondary mortality/morbidity composite comprised death and major morbidity including NEC, late onset sepsis, chronic lung disease or severe retinopathy of prematurity. Late onset sepsis was defined as a positive culture from blood, cerebrospinal fluid, catheter or suprapubic urine at $>5$ days after birth. A confirmed case of NEC was defined as stage 2 or 3 by the Modified Bell Staging Criteria [75]. Infants were classified as having chronic lung disease as assessed at 36 weeks postconception by NIH criteria [76]. Severe ROP (Stage 4 or 5) was defined according to International criteria or if laser surgery or intraocular anti-vascular injection was required [77-79].

Weight $(+/-2 \mathrm{~g})$, length $(+/-0.1 \mathrm{~cm})$ and head circumference $(+0.1 \mathrm{~cm})$ were measured weekly during hospitalization and at routine post-discharge clinic visits using standardized procedures and precision equipment as previously described $[80,81]$. To account for the different GA of infants, z-scores for anthropometric measurements are computed using the Fenton preterm growth charts and the World Health Organization Growth Standard after 50 weeks gestational age [82]. Changes in weight as a consequence of the intervention will be specifically examined in relation to gains in length and head circumference as there is little evidence that weight gain alone (i.e. fat mass gain) will benefit the long-term outcome of infants.

Exploratory variables include feeding tolerance and nutrient intakes during the feeding intervention. The volume and estimated energy/nutrient density of study milk and other sources of nutrition (e.g. parenteral 


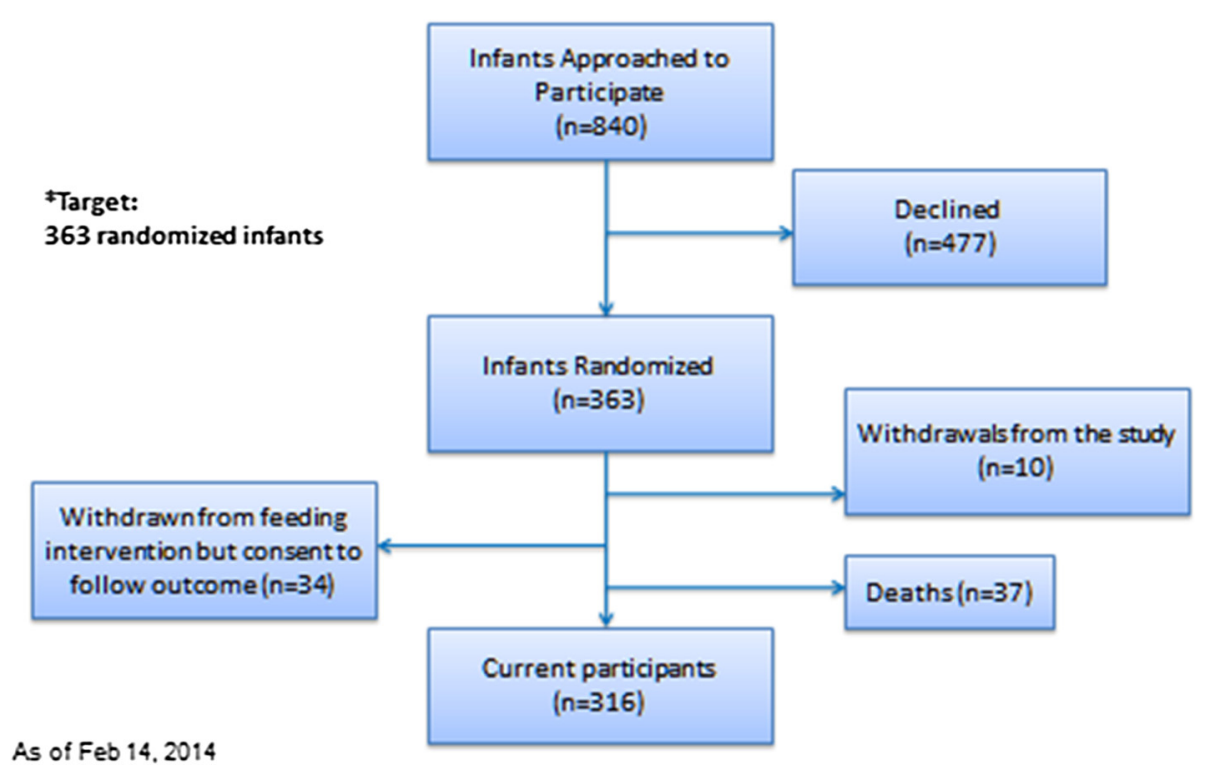

Figure 2 Subject disposition to date.

nutrition, mother's own milk, vitamin supplements) were extracted prospectively from medical records by study staff during the feeding intervention. Feeding tolerance will be assessed by describing the days to full enteral feeding $(150 \mathrm{ml} / \mathrm{kg} / \mathrm{d})$ and number of days feedings were withheld.

In addition, a health economic analysis of the use of pasteurized donor milk compared to preterm formula as a supplement to mother's own milk is being conducted. The specific objectives of the health economic analyses are:

(i) To measure and compare the relevant health and non-health costs of neonatal care to 18 months, for VLBW infants fed donor milk or preterm formula as a supplement.

(ii) As appropriate, use measured costs in conjunction with the efficacy data from the clinical trial to estimate the cost per five-point improvement in BSID-III through use of donor milk in VLBW infants.

(iii) To use decision-analytic modeling and secondary literature sources to estimate the long-term health and non-health costs, as well as long-term quality of life outcomes and cost per quality adjusted life year, for enrolled infants, based on outcomes measured to 18 months CA.

All relevant health economic data is collected prospectively monthly from the time of study enrolment until 18 months CA.

Although some differences in resource utilization between treatment and control groups will be related to the costs of donor milk and potentially to differential neonatal therapeutic requirements if one group has improved growth or fewer adverse events such as NEC, there may be longer-term differences in costs if donor administration is associated with improvements in neurodevelopment [83]. Unfortunately, the measurement of cost-related outcomes beyond the 18 month endpoint for the clinical trial data collection is not feasible. Instead, a decision-analytic model will be constructed to synthesize longer-term cost effectiveness estimates in a secondary analysis [84]. In order to balance the importance of long-term cost-effectiveness with the potentially reduced validity of literature-supplemented cost estimates, results will be reported primarily in terms of measured cost-effectiveness to 18 months, and secondarily in terms of modeled cost-effectiveness through the lifetime. The former results will be of interest primarily to hospital decision makers and third-party payers, while the latter will more strictly maintain the societal perspective important to the broader clinical and policymaking audience.

\section{Statistical analyses}

Using a 5 point difference in composite cognitive scores at 18 months CA, with $80 \%$ power (alpha level of 0.05 ), and an estimated standard deviation in each feeding group of 15, we estimated that we required 142 infants in each feeding arm. We assumed a 10\% loss to followup during the feeding intervention and an additional $10 \%$ loss to follow-up after discharge, thus necessitating 176 infants to be randomized in each of the two feeding groups. As the number of infants withdrawn from the study exceeded $10 \%$, primarily due to infant death, we 
overenrolled by 11 subjects to produce a final sample size of 363 subjects.

Analyses will be carried out using SAS Version 9.1 (SAS Institute, Cary, NC, USA). Descriptive statistics will be calculated for all variables of interest. Continuous measures will be summarized using means and standard deviations whereas categorical measures will be summarized using counts and percentages. The primary analysis for this intent-to-treat study will include all infants as randomized, regardless of adherence with the feeding protocol. The initial analysis will be a comparison of means (cognitive composite score) between the 2 groups at 18 months CA. A generalized linear model will carry out this comparison, controlling for length of treatment and adjusting for correlation of observations taken at the same centre. Sex, birth weight strata $(<1000,1000-$ $1499 \mathrm{~g}$ ), use of antenatal steroids, multiple birth, a count of key morbidities and duration of mother's own milkfeeding are prognostic of neurodevelopmental outcome, and for this reason we will perform a secondary analysis which will include a regression model adjusted for the aforementioned characteristics $[4,6,13]$.

Children who cannot be tested on the BSID-III due to disability, severe delay or who perform below the threshold of the test for individual composite scores (cognitive, language motor) will be assigned a score of 49 [7]. The scores will be computed by trained individuals who have established inter rater reliability $\left(R^{2}=80\right)$ and who are blind to study group. Other missing data will be handled using methods of multiple imputation.

\section{Discussion}

More than 2,700 VLBW( $<1500$ grams $)$ babies are born in Canada each year with a length of hospital stay varying from 59 to 113 days compared to an average of 2-3 days for a healthy term infant $[85,86]$. Although children born of VLBW represent a small proportion of children born in Canada, they represent an important cause of neurodevelopmental delay and disability in childhood and consume a disproportionately large amount of health care dollars [3,85,87]. Interventions that can promote better health and development of these children can thus have a large impact. Although, in older trials, donor milk was protective against the development of NEC, there have been no studies to date assessing long-term outcome following donor milk supplementation in current era NICUs.

The societal implications of a 5 point difference in the cognitive composite score on the Bayley Scales of Infant and Toddler Development (BSID) are substantial [15]. Currently, half of VLBW infants require special education services at school [88-91], even among children without neurosensory impairment [92] which has been shown to translate into a lower level of academic achievement in adulthood (e.g. number of high school graduates) [93,94].
Vohr et al. argue that a 5 point difference could translate into a reduction in the number of children requiring special education services, associated costs, and improve long-term academic achievement [15]. In a detailed analysis of the economic gains realized as a result of lowering environmental lead exposure in the U.S., Grosse et al. estimated that the 5 point improvement in cognitive scores realized amongst 1-5 year old children equates to a 9 to $12 \%$ increase in work productivity in adulthood [83].

Anderson et al. previously showed a 5 point improvement in cognitive outcome in low birth weight infants fed mother's own milk instead of formula [9]. Given the VLBW infants in this RCT were considerably smaller than those in the Anderson meta-analysis, it is reasonable to assume our effect size may be larger as serious morbidity (e.g. NEC and sepsis), poor growth, and longterm neurodevelopmental sequelae are inversely related to gestation at birth $[2,3]$; hence, there is a much greater opportunity for human milk to improve BSID-III scores.

The 90 day intervention period was chosen as at the time of initiation of this trial, the only available RCT on this research question reflective of current clinical practice also used a 90 day period [30]. This will facilitate a comparison of results from the two studies. Ninety days also reflected the average length of hospital stay of VLBW infants from the recruiting NICUs at the study initiation. The duration of the exposure is sufficient to observe differences in neurodevelopmental outcome at 18 months as Lucas et al. demonstrated differences in BSID scores at 18 months CA between infants $(<1850 \mathrm{~g})$ fed mother's own milk versus formula for an average duration of 4 weeks during initial hospitalization [74]. These differences translated into a higher IQ (8.3 points) at 7.5 years of age even after controlling for maternal education and social class $(p<0.0001)$.

\section{Health economic impact}

It has been estimated that the incremental direct medical costs of preterm birth in the United States exceed 26 billion dollars [93,94]. Despite these significant tallies, most economic analyses in the literature have focused on the global package of neonatal care or on new technologies or therapies such as surfactant, nitric oxide or erythropoietin. However, less glamorous components in the treatment of VLBW infants, such as optimal feeding, may also involve significant expenditures due to their frequency of use. It is important in an era of increasing financial constraint to establish not only the evidence for clinical efficacy of such therapies, but also the evidence for their value-for-money. Furthermore, if such economic information is to conform to the standards of evidence used for clinical efficacy and remain free of systematic bias, it is essential that data are collected prospectively, in conjunction with RCTs, whenever possible. 
Although one study has used modeling techniques to estimate the cost implications of the use of donor milk $[95,96]$ and a second report examined the costs of preventing necrotizing enterocolitis in an exclusive human milk diet including human based fortifier [97], there has been no direct measurement of cost of donor milk use alongside a randomized trial or other strong study design. The establishment of a donor milk bank requires a substantial commitment of resources, due to the volume of product handled and the need for rigorous safeguards against contamination, misidentification or infection. The costs of avoiding these risks may, indeed, be of a similar magnitude to blood banking. Conversely, if the use of donor milk lowers the incidence of adverse consequences such as NEC or improves growth or neurodevelopmental status, the costs for the intervention group may be lower in the medium or long-term. The balance of short-term and long-term costs and savings can only be estimated through formal economic evaluation.

Results of this pragmatic trial will determine the most effective supplement for VLBW infants when mother's own milk is unavailable to support neurocognitive development. We anticipate data from this study, including a health economic analysis, will immediately impact the development of milk banks in Canada and beyond.

\section{Abbreviations \\ BSID-III: Bayley Scales of Infant Development, $3^{\text {rd }}$ edition; CA: Corrected age; DoMINO: Donor milk for improved neurodevelopmental outcomes; HMBANA: Human milk banking association of North America MOM, Mother's own milk; NIH: National Institutes of Health; NEC: Necrotizing enterocolitis; NICU: Neonatal intensive care unit; PDM: Pasteurized donor milk; ROP: Retinopathy of Prematurity; VLBW: Very low birth weight.}

\section{Competing interests}

SU is the medical director of a human milk bank for which both SU and DLO are the co-chairs of the Advisory Board for the milk bank. All authors declare no financial competing interests.

\section{Authors' contributions}

SU, SG and DLO are the primary investigators for the DoMINO trial and thus contributed substantially to the development of the protocol as well as drafting and critically revising the manuscript. JZ is a co-investigator for the DoMINO trial, responsible the health economics evaluation and for critically revising this manuscript. All authors read and approved the final manuscript.

\section{Acknowledgements}

The authors wish to acknowledge key members of the GTA DoMINO feeding group including: Alex Kiss, Elizabeth Asztalos, Eugene Ng, Andrea Nash and Sabrina Wong (Sunnybrook Health Sciences Center); Nicole Bando, Joan Brennan, and Joanne Rovet (The Hospital for Sick Children); Kirsten Kotsopoulos (Mount Sinai Hospital); Chris Fusch (Hamilton Health Sciences Centre); Anwar Asady, Ann Bayliss and Sandra Gabrielle (Trillium Health Partners), Shirley Sit and Sue Ekserci (Humber River Regional Hospital); Mahmud AlMadani (Lakeridge Health); Munesh Singh (Markham Stouffville Hospital); Shaheen Doctor (North York General Hospital); Karen Chang (Rouge Valley Health System); Douglas Campbell (Saint Michaels Hospital); Peter Azzopardi (The Scarborough Hospitals); David Gryn (Mackenzie Health); Simone Vaz (William Osler Health System); Jelena Popovic (Toronto East General); Debby Arts-Rodas (St Joseph's Health Care); Carol Williams and Charmaine Van Schaik (Southlake Regional Health Centre). The authors further wish to acknowledge the invaluable assistance of Debbie Stone, lactation consultant manager of the Rogers Hixon Ontario Human Milk Bank.

\section{Author details}

${ }^{1}$ Mount Sinai Hospital and the University of Toronto, 600 University Avenue, 19-231, Toronto, Ontario, M5G 1X5, Canada. ${ }^{2}$ Trillium Health Partners, 2200 Eglinton Ave West, Mississauga, Ontario, L5M 2 N1, Canada. ${ }^{3}$ Beth Israel Deaconess Med Center, Neonatology, Rose 318330 Brookline Ave, Boston, MA, 02215, USA. ${ }^{4}$ University of Toronto and The Hospital for Sick Children, 327 Fitzgerald Building, 150 College Street, Toronto, Ontario, M5S 3E2, Canada.

Received: 23 February 2014 Accepted: 1 May 2014

Published: 13 May 2014

\section{References}

1. Qiu X, Lee SK, Tan K, Piedboeuf B, Canning R: Comparison of singleton and multiple-birth outcomes of infants born at or before 32 weeks of gestation. Obstet Gynecol 2008, 111(2 Pt 1):365-371.

2. Stoll BJ, Hansen NI, Bell EF, Shankaran S, Laptook AR, Walsh MC, Hale EC, Newman NS, Schibler K, Carlo WA, Kennedy KA, Poindexter BB, Finer NN Ehrenkranz RA, Duara S, Sanchez PJ, O'Shea TM, Goldberg RN, Van Meurs KP, Faix RG, Phelps DL, Frantz ID 3rd, Watterberg KL, Saha S, Das A, Higgins RD, Eunice Kennedy Shriver National Institute of Child Health and Human Development Neonatal Research Network: Neonatal outcomes of extremely preterm infants from the NICHD Neonatal Research Network. Pediatrics 2010, 126:443-456.

3. Saigal S, Doyle LW: An overview of mortality and sequelae of preterm birth from infancy to adulthood. Lancet 2008, 371:261-269.

4. Bassler D, Stoll BJ, Schmidt B, Asztalos EV, Roberts RS, Robertson CM, Sauve RS: Using a count of neonatal morbidities to predict poor outcome in extremely low birth weight infants: added role of neonatal infection. Pediatrics 2009, 123:313-318.

5. Ehrenkranz RA, Dusick AM, Vohr BR, Wright LL, Wrage LA, Poole WK: Growth in the neonatal intensive care unit influences neurodevelopmental and growth outcomes of extremely low birth weight infants. Pediatrics 2006, 117:1253-1261.

6. Schmidt B, Asztalos EV, Roberts RS, Robertson CM, Sauve RS, Whitfield MF: Impact of bronchopulmonary dysplasia, brain injury, and severe retinopathy on the outcome of extremely low-birth-weight infants at 18 months: results from the trial of indomethacin prophylaxis in preterms. JAMA 2003, 289:1124-1129.

7. Stoll BJ, Hansen NI, Adams-Chapman I, Fanaroff AA, Hintz SR, Vohr B, Higgins RD: Neurodevelopmental and growth impairment among extremely low-birth-weight infants with neonatal infection. JAMA 2004 292:2357-2365

8. Vohr BR, Wright LL, Dusick AM, Mele L, Verter J, Steichen JJ, Simon NP, Wilson DC, Broyles S, Bauer CR, Delaney-Black V, Yolton KA, Fleisher BE, Papile LA, Kaplan MD: Neurodevelopmental and functional outcomes of extremely low birth weight infants in the National Institute of Child Health and Human Development Neonatal Research Network, 1993-1994. Pediatrics 2000, 105:1216-1226.

9. Anderson JW, Johnstone BM, Remley DT: Breast-feeding and cognitive development: a metaanalysis. Am J Clin Nutr 1999, 70:525-535.

10. Horwood $\amalg$, Darlow BA, Mogridge N: Breast milk feeding and cognitive ability at 7-8 years. Arch Dis Child Fetal Neonatal Ed 2001, 84:F23-F27.

11. Horwood $L$, Fergusson DM: Breastfeeding and later cognitive and academic outcomes. Pediatrics 1998, 101:E9.

12. Horwood L, Mogridge N, Darlow BA: Cognitive, educational, and behavioural outcomes at 7 to 8 years in a national very low birthweight cohort. Arch Dis Child Fetal Neonatal Ed 1998, 79:F12-F20

13. O'Connor DL, Jacobs J, Hall R, Adamkin D, Auestad N, Castillo M, Connor WE, Connor SL, Fitzgerald K, Groh-Wargo S, Hartmann EE, Janowsky J, Lucas A, Margeson D, Mena P, Neuringer M, Ross G, Singer L, Stephenson T, Szabo J, Zermon V: Growth and development of premature infants fed predominantly human milk, predominantly premature infant formula, or a combination of human milk and premature formula. J Pediatr Gastroenterol Nutr 2003, 37:437-446.

14. Vohr BR, Poindexter BB, Dusick AM, McKinley LT, Wright LL, Langer JC, Poole WK, National Institute of Child Health and Human Development National Research Network: Beneficial effects of breast milk in the neonatal intensive care unit on the developmental outcome of extremely low birth weight infants at 18 months of age. Pediatrics 2006, 118:e115-e123. 
15. Vohr BR, Poindexter BB, Dusick AM, McKinley LT, Higgins RD, Langer JC, Poole WK, National Institute of Child Health and Human Development National Research Network: Persistent beneficial effects of breast milk ingested in the neonatal intensive care unit on outcomes of extremely low birth weight infants at 30 months of age. Pediatrics 2007, 120:e953-e959.

16. Schanler RJ: Evaluation of the evidence to support current recommendations to meet the needs of premature infants: the role of human milk. Am J Clin Nutr 2007, 85:625S-628S.

17. World Health Organization: Global Strategies for Infant and Young Child Feeding. Resolution Passes at: Fifty-fourth World Health Assembly. 2001

18. Section on Breastfeeding: Breastfeeding and the use of human milk. Pediatrics 2012, 129:e827-e841.

19. Canadian Paediatric Society, Dietitians of Canada, Health Canada: Nutrition for Healthy Term Infants. [http://www.hc-sc.gc.ca/fn-an/nutrition/infantnourisson/recom/index-eng.php]

20. Callen J, Pinelli J: A review of the literature examining the benefits and challenges, incidence and duration, and barriers to breastfeeding in preterm infants. Adv Neonatal Care 2005, 5:72-88.

21. Human Milk Banking Association of North America. [https://www.hmbana.org/]

22. Quigley MA, Henderson G, Anthony MY, McGuire W: Formula milk versus donor breast milk for feeding preterm or low birth weight infants. Cochrane Database Syst Rev 2007, 4, CD002971.

23. O'Connor DL, Merko S, Brennan J: Human milk feeding of very-low-birthweight infants during initial hospitalization and after discharge. Nutr Today 2004, 39:102-111.

24. Hintz SR, Kendrick DE, Stoll BJ, Vohr BR, Fanaroff AA, Donovan EF, Poole WK, Blakely ML, Wright L, Higgins R, NICHD Neonatal Research Network: Neurodevelopmental and growth outcomes of extremely low birth weight infants after necrotizing enterocolitis. Pediatrics 2005, 115:696-703.

25. Davies DP: Adequacy of expressed breast milk for early growth of preterm infants. Arch Dis Child 1977, 52:296-301.

26. Gross SJ: Growth and biochemical response of preterm infants fed human milk or modified infant formula. N Engl J Med 1983, 308:237-241.

27. Lucas A, Gore SM, Cole TJ, Bamford MF, Dossetor JFB, Barr I, Dicarlo L, Cork S, Lucas PJ: Multicentre trial on feeding low birthweight infants: effects of diet on early growth. Arch Dis Child 1984, 59:722-730.

28. Lucas A, Morley R, Cole TJ, Gore SM, Davis JA, Bamford MFM, Dossetorii JFB: Early diet in preterm babies and developmental status in infancy. Arch Dis Child 1989, 64:1570-1578.

29. Räihä NC, Heinonen K, Rassin DK, Gaull GE: Milk protein quantity and quality in low-birthweight infants: Metabolic responses and effects on growth. Pediatrics 1976, 57:659-684

30. Schanler RJ, Lau C, Hurst NM, Smith EO: Randomized trial of donor human milk versus preterm formula as substitutes for mothers' own milk in the feeding of extremely premature infants. Pediatrics 2005, 116:400-406.

31. Schultz K, Soltész G, Mestyán J: The metabolic consequences of human milk and formula feeding in premature infants. Acta Paediatr Scand 1980, 69:647-652

32. Tyson JE, Lasky RE, Mize CE, Richards CJ, Blair-Smith N, Whyte R, Beer AE: Growth, metabolic response, and development in very-low-birth-weigh infants fed banked human milk or enriched formula. Neonatal findings. J Pediatr 1983, 103:95-104

33. Hack M, Breslau N, Weissman B, Aram D, Klein N, Borawski E: Effect of very low birth weight and subnormal head size on cognitive abilities at school age. N Engl J Med 1991, 325(4):231-237.

34. Latal-Hajnal B, von Siebenthal K, Kovari H, Bucher HU, Largo RH: Postnatal growth in VLBW infants: significant association with neurodevelopmental outcome. J Pediatr 2003, 143:163-170.

35. Human Milk Banking Association of North America: Milk Banking Guidelines. Raleigh, North Carolina: 2013

36. Wojcik KY, Rechtman DJ, Lee ML, Montoya A, Medo ET: Macronutrient analysis of a nationwide sample of donor breast milk. J Am Diet Assoc 2009, 109:137-140.

37. Valentine CJ, Morrow G, Fernandez S, Gulati P, Bartholomew D, Long D, Welty SE, Morrow AL, Rogers LK: Docosahexaneoic acid and amino acid contents in pasteurized donor milk are low for preterm infants. J Pediatr 2010, 157:906-910.

38. Gross SJ, Buckley RH, Wakil SS, McAllister DC, David RJ, Faix RG: Elevated IgA concentration in milk produced by mothers delivered of preterm infants. J Pediatr 1981, 99:389-393.
39. Jensen G, Neville MC (Eds): Human Milk: Milk Components and Methodologies. New York: Plenum Publishing Corporation; 1985.

40. Gross SJ, David RJ, Bauman L, Tomarelli RM: Nutritional composition of milk produced by mothers delivering preterm. J Pediatr 1980, 96:641-644.

41. Donnelly-Vanderloo M, O'Connor DL: Impact of pasteurization and procedures commonly used to rethermalize stored human milk on folate content. Nutr Res 1994, 14:1305

42. Van Zoeren-Grobben D, Schrijver J, Van den Berg H, Berger HM: Human milk vitamin content after pasteurisation, storage, or tube feeding. Arch Dis Child 1987, 62:161-165.

43. Ley SH, Hanley AJ, Stone D, O'Connor DL: Effects of pasteurization on adiponectin and insulin concentrations in donor human milk. Pediatr Res 2011, 70:278-281.

44. Henderson TR, Fay TN, Hamosh M: Effect of pasteurization on long chain polyunsaturated fatty acid levels and enzyme activities of human milk. J Pediatr 1998, 132:876-878.

45. Lawrence RA: Storage of human milk and the influence of procedures on immunological components of human milk. Acta Paediatr 1999, 88(Suppl 430):14-18.

46. Liebhaber M, Asquith MT, Olds-Arroyo L, Sunshine P: Alterations of lymphocytes and of antibody content of human milk after processing. J Pediatr 1977, 91:897-900.

47. Cossey $V$, Jeurissen A, Bossuyt $X$, Schuermans A: Effect of pasteurization on the mannose-binding lectin activity and the concentration of CD14 in human milk. J Hosp Infect 2009, 73:96-97.

48. Braga LP, Palhares DB: Effect of evaporation and pasteurization in the biochemical and immunological composition of human milk. J Pediat (Rio J) 2007, 83:59-63.

49. Fidler N, Sauerwald TU, Koletzko B, Demmelmair H: Effects of human milk pasteurization and sterilization on available fat content and fatty acid composition. J Pediatr Gastroenterol Nutr 1998, 27:317-322.

50. Goes HC, Torres AG, Donangelo CM, Trugo NM: Nutrient composition of banked human milk in Brazil and influence of processing on zinc distribution in milk fractions. Nutrition 2002, 18:590-594.

51. Wardell JM, Hill CM, D'Souza SW: Effect of pasteurization and of freezing and thawing human milk on its triglyceride content. Acta Paediatr Scand 1981, 70:467-471.

52. daCosta RS, doCarmo MG, Saunders C, deJesus EF, Lopes RT, Simabuco SM: Characterization of iron, copper and zinc levels in the colostrum of mothers of term and pre-term infants before and after pasteurization. Int J Food Sci Nutr 2003, 54:111-117.

53. Silvestre D, Ruiz P, Martinez-Costa C, Plaza A, Lopez MC: Effect of pasteurization on the bactericidal capacity of human milk. J Hum Lact 2008, 24:371-376

54. Ewaschuk JB, Unger S, O'Connor DL, Stone D, Harvey S, Clandinin MT, Field $\mathrm{CJ}$ : Effect of pasteurization on selected immune components of donated human breastmilk. J Perinatol 2011, 31:593-598.

55. Goelz R, Hihn E, Hamprecht K, Dietz K, Jahn G, Poets C, Elmlinger M: Effects of different CMV-heat-inactivation methods on growth factors in human breast milk. Pediatr Res 2009, 65:458-461.

56. Untalan PB, Keeney SE, Palkowetz KH, Rivera A, Goldman AS: Heat susceptibility of interleukin-10 and other cytokines in donor human milk. Breastfeed Med 2009, 4:137-144.

57. Lepri L, Del Bubba M, Maggini R, Donzelli GP, Galvan P: Effect of pasteurization and storage on some components of pooled human milk. J Chromatogr B Biomed Sci App/ 1997, 704:1-10.

58. Czank C, Prime D, Hartmann B, Simmer K, Hartmann PE: Retention of the immunological proteins of pasteurized human milk in relation to pasteurizer design and practice. Pediatr Res 2009, 66:374-379.

59. Viazis S, Farkas BE, Allen JC: Effects of High-Pressure Processing on Immunoglobulin A and Lysozyme Activity in Human Milk. J Hum Lact 2007, 23:253-261.

60. Evans TJ, Ryley HC, Neale LM, Dodge JA, Lewarne VM: Effect of storage and heat on antimicrobial proteins in human milk. Arch Dis Child 1978, 53:239-241

61. Ford JE, Law BA, Marshall VM, Reiter B: Influence of the heat treatment of human milk on some of its protective constituents. J Pediatr 1977 90:29-35.

62. Koenig A, de Albuquerque Diniz EM, Barbosa SF, Vaz FA: Immunologic factors in human milk: the effects of gestational age and pasteurization. J Hum Lact 2005, 21:439-443. 
63. Silvestre D, Ferrer E, Gaya J, Jareno E, Miranda M, Muriach M, Romero FJ: Available lysine content in human milk: stability during manipulation prior to ingestion. Biofactors 2006, 26:71-79.

64. Bertino E, Coppa GV, Giuliani F, Coscia A, Gabrielli O, Sabatino G, Sgarrella $M$, Testa T, Zampini $L$, Fabris $C$ : Effects of Holder pasteurization on human milk oligosaccharides. Int J Immunopathol Pharmacol 2008, 21:381-385.

65. McPherson RJ, Wagner CL: The effect of pasteurization on transforming growth factor alpha and transforming growth factor beta 2 concentrations in human milk. Adv Exp Med Biol 2001, 501:559-566.

66. Ewaschuk JB, Unger S, Harvey S, O'Connor DL, Field CJ: Effect of pasteurization on immune components of milk: implications for feeding preterm infants. Appl Physiol Nutr Metab 2011, 36:175-182.

67. Tully DB, Jones F, Tully MR: Donor milk: what's in it and what's not. J Hum Lact 2001, 17:152-155.

68. Lindquist $\mathrm{S}$, Hernell $\mathrm{O}$ : Lipid digestion and absorption in early life: an update. Curr Opin Clin Nutr Metab Care 2010, 13:314-320.

69. Manzoni P, Stolfi I, Cattani S, Messner H, Laforgia N, Romeo MG, Bollani L, Rinaldi M, Gallo E, Quercia M, Maule M, Mostert M, Decembrino L, Magaldi R, Mosca F, Vagnarelli F, Memo L, Betta PM, Stronati M, Farina D, Italian Task Force for the Study and Prevention of Neonatal Fundal Infections-the Italian Society of Neonatology: Bovine lactoferrin supplementation prevents invasive fungal infections in very low birth weight infants: a randomized controlled trial. Pediatrics 2012, 129:116-123.

70. Venkatesh M, Abrams S: Can lactoferrin prevent neonatal sepsis and necrotizing enterocolitis? Expert Rev Anti Infect Ther 2009, 7:515-525.

71. Tsang RC, Uauy R, Koletzko B, Zlotkin S: Nutrition of the Preterm Infant: Scientific Basis and Practical Guidelines Second Edition. Cincinnati, $\mathrm{OH}$ : Digital Educational Publishing; 2005

72. Institute of Medicine: Dietary Reference Intakes for Energy, Carbohydrate, Fate, Fatty Acids, Cholesterol, Protein, and Amino Acids. Washington DC: The National Academies Press; 2005

73. Bayley N: Bayley Scales of Infant Development. San Antonio: The Psychological Corporation; 2006

74. Lucas A, Morley R, Cole TJ: Randomised trial of early diet in preterm babies and later intelligence quotient. BMJ 1998, 317:1481-1487.

75. Bell MJ, Ternberg JL, Feigin RD, Keating JP, Marshall R, Barton L, Brotherton $\mathrm{T}$ : Neonatal necrotizing enterocolitis. Therapeutic decisions based upon clinical staging. Ann Surg 1978, 187:1-7.

76. Ehrenkranz RA, Walsh MC, Vohr BR, Jobe AH, Wright LL, Fanaroff AA, Wrage LA, Poole K, National Institutes of Child Health and Human Development Neonatal Research Network: Validation of the National Institutes of Health consensus definition of bronchopulmonary dysplasia. Pediatrics 2005, 116:1353-1360

77. The Committee for the Classification of Retinopathy of Prematurity: An international classification of retinopathy of prematurity. Arch Ophthalmol 1984, 102:1130-1134

78. The International Committee for the Classification of the Late Stages of Retinopathy of Prematurity: An international classification of retinopathy of prematurity. II. The classification of retinal detachment. Arch Ophthalmol 1987, 105:906-912

79. Section on Ophthalmology American Academy of Pediatrics, American Academy of Ophthalmology, American Association for Pediatric Ophthalmology and Strabismus: Screening examination of premature infants for retinopathy of prematurity. Pediatrics 2006, 117:572-576.

80. Aimone A, Vaughan J, Ward W, Jefferies A, Campbell DM, Asztalos E, Feldman M, Vaughan J, Westall C, Whyte H, O'Connor DL, Post-Discharge Feeding Group: Growth and body composition of human milk-fed premature infants provided with extra energy and nutrients early after hospital discharge: one year follow-up. J Pediatr Gastroenterol Nutr 2009, 49:456-466

81. O'Connor DL, Khan S, Weishuhn K, Vaughan J, Jefferies A, Campbell DM, Asztalos E, Feldman M, Rovet J, Westall C, Whyte H, Post-Discharge Feeding Study Group: Growth and nutrient intakes of human milk-fed preterm infants provided with extra energy and nutrients after hospital discharge. Pediatrics 2008, 121:766-776.

82. Fenton TR, Kim JH: A systematic review and meta-analysis to revise the Fenton growth chart for preterm infants. BMC Pediatr 2013, 13:59.

83. Grosse SD, Matte TD, Schwartz J, Jackson RJ: Economic gains resulting from the reduction in children's exposure to lead in the United States. Environ Health Perspect 2002, 110:563-569.
84. O'Brien B: Economic evaluation of pharmaceuticals. Frankenstein's monster of vampire of trials? Med Care 1996, 34(12 Suppl):DS99-DS108.

85. Canadian Institute for Health Information: Giving Birth in Canada: The Costs. [http://publications.gc.ca/collections/Collection/H118-38-2006E.pdf]

86. The Canadian Neonatal Network Annual Report 2012. [http://www. canadianneonatalnetwork.org/Portal/LinkClick.aspx?fileticket=lsGgJQ EDJ8\% 3D\&tabid=39]

87. Boulet SL, Schieve LA, Boyle CA: Birth weight and health and developmental outcomes in US children, 1997-2005. Matern Child Health J 2011, 15:836-844

88. Hack M, Flannery DJ, Schluchter M, Cartar L, Borawski E, Klein N: Outcomes in young adulthood for very-low-birth-weight infants. N Engl J Med 2002 346:149-157.

89. Litt J, Taylor HG, Klein N, Hack M: Learning disabilities in children with very low birthweight: prevalence, neuropsychological correlates, and educational interventions. J Lear Disabil 2005, 38:130-141.

90. Saigal S: Follow-up of very low birthweight babies to adolescence. Semin Neonatol 2000, 5:107-118.

91. Taylor HG, Minich N, Bangert B, Filipek PA, Hack M: Long-term neuropsychological outcomes of very low birth weight: associations with early risks for periventricular brain insults. J Int Neuropsychol Soc 2004, 10:987-1004.

92. Saigal S, Hoult LA, Streiner DL, Stoskopf BL, Rosenbaum PL: School difficulties at adolescence in a regional cohort of children who were extremely low birth weight. Pediatrics 2000, 105:325-331.

93. Waitzman NJ, Rogowski J: Societal costs of preterm birth. In Preterm Birth Causes, Consequences and Prevention. Edited by Behrman R, Stith-Butler A. Washigton DC: The National Academies Press; 2006:398-429.

94. Zupancic JAF: A systematic review of costs associated with preterm birth In Preterm Birth: Causes, Consequences and Prevention. Edited by Behrman R, Stith-Butler A. Washigton DC: The National Academies Press; 2006.

95. Arnold LD: The cost-effectiveness of using banked donor milk in the neonatal intensive care unit: prevention of necrotizing enterocolitis. J Hum Lact 2002, 18:172-177.

96. Arnold LD: Cost savings through the use of donor milk: case histories. J Hum Lact 1998, 14:255-258.

97. Ganapathy V, Hay JW, Kim JH: Costs of necrotizing enterocolitis and costeffectiveness of exclusively human milk-based products in feeding extremely premature infants. Breastfeed Med 2012, 7:29-37.

doi:10.1186/1471-2431-14-123

Cite this article as: Unger et al:: DoMINO: Donor milk for improved neurodevelopmental outcomes. BMC Pediatrics 2014 14:123.

\section{Submit your next manuscript to BioMed Central and take full advantage of:}

- Convenient online submission

- Thorough peer review

- No space constraints or color figure charges

- Immediate publication on acceptance

- Inclusion in PubMed, CAS, Scopus and Google Scholar

- Research which is freely available for redistribution 